\title{
A EXPERIÊNCIA AFRO-AMERICANA NUMA PERSPECTIVA COMPARATIVA: \\ A SITUAÇÃO ATUAL DO DEBATE SOBRE A ESCRAVIDÃO NAS AMÉRICAS *
}

Herbert S. Klein

$\mathrm{G}$ ostaria de retomar um tema que tem sido muito negligenciado nas discussões recentes sobre a diáspora africana nas Américas, que é a comparação das diferenças e semelhanças entre os regimes escravistas e sua influência na integração pós-abolição de africanos e afro-americanos. Este é um tema que remonta aos primeiros estudos modernos sobre africanos nas Américas. De Fernando Ortiz, em Cuba, a Nina Rodrigues, no Brasil, verificou-se, em geral, uma percepção entre os estudiosos latino-americanos de que houve diferenças na forma como os africanos foram integrados nessas diversas sociedades. ${ }^{1}$ Estudiosos norte-americanos, como Donald Pierson, Frank Tannenbaum, Stanley Elkins e Carl Degler, tentaram colocar a experiência dos Estados Unidos nesse quadro comparativo. ${ }^{2}$ Durante algum

Versão revisada (fev-mar 2011) de comunicação apresentada na Blacks in Latin America Conference, Harvard University, janeiro de 2011. O autor gostaria de agradecer os comentários feitos pelo parecerista da Afro-Ásia. Tradução de Mariângela de Mattos Nogueira

** Professor das universidades de Columbia e Stanford.

1 Raymundo Nina Rodrigues, Os africanos no Brasil, São Paulo: Companhia Editora Nacional, 1935; e Fernando Ortiz, Hampa Afro-Cubana: los negros esclavos, Havana: Revista Bimestre Cubana, 1916.

2 Donald Pierson, Negroes in Brazil, a Study of Race Contact at Bahia, Chicago: University of Chicago Press, 1942; Frank Tannenbaum, Slave and Citizen, the Negro in the Americas, Nova York: Alfred A. Knopf, 1947; Stanley M. Elkins, Slavery: A Problem in American 
tempo, entre as décadas de 1940 e 1970, verificou-se que a análise comparativa ensejou algumas interessantes questões e debates sobre instituições, culturas e organizações sociais. ${ }^{3}$ Mas esse debate desapareceu com a rejeição dos estudos comparativos na historiografia norte-americana, por um lado, e, por outro, com a concentração da historiografia latino-americana em detalhados estudos locais. Ambos os movimentos negligenciaram o retorno à questão comparativa.

No passado, para os autores latino-americanos, o duro racismo dos Estados Unidos, no período pós-escravidão, resultara de um regime escravista mais restritivo do que outros nas Américas. O modelo birracial encontrado nos Estados Unidos, o sistema legal racista extremamente severo do século XIX, a que Ortiz se referiu como a "lei de ferro da escravidão", ${ }^{4}$ a duradoura hostilidade para com os negros libertos e sua marginalização entre as pessoas livres, no sul do país, na era segregacionista, foram tomados no sentido de que os Estados Unidos seriam diferentes da maioria das sociedades latino-americanas. Isso não quer dizer que esses autores não reconhecessem o racismo inerente a todos os sistemas pós-escravistas nas Américas, mas que consideravam os Estados Unidos como um caso à parte.

Quase tanta hostilidade quanto a norte-americana em relação ao ex-escravo e sua condição de livre já pode ser percebida nas leis das colônias e estados do norte e do sul dos Estados Unidos desde o século XVIII. Nenhum estado do sul, e apenas alguns do norte, permitia o voto de libertos no século XIX. ${ }^{5}$ A maioria dos estados do norte e do sul proibia liberto(a)s de se casarem com branco(a)s e dissolvia qualquer

Institutional and Intellectual Life, Chicago: University of Chicago Press, 1959; e Carl N. Degler, Neither Black Nor White: Slavery and Race Relations In Brazil and the United States, Nova York: Macmillan, 1971.

3 O trabalho do sociólogo brasileiro Gilberto Freyre foi extremamente importante nesse debate. Ver especialmente Casa grande e senzala: formação da família brasileira sob o regime de economia patriarcal, Rio de Janeiro: José Olympio, 1943.

4 Ortiz, Hampa afro-cubana, p. 362.

5 Essas proibições ao voto foram declaradas em Delaware em 1787; Kentucky, 1799, Maryland, 1809; Louisiana, 1812; Mississipi, 1817; Alabama, 1819, Nova Jersey, 1820, Missouri, 1820; Tennessee, 1834; Pennsylvania, 1838; Virginia, 1849; District of Columbia, 1851; Oregon, 1859; Indiana, 1851. Esta e todas as subsequentes referências legais vêm do consagrado repertório dessas leis em John Codman Hurd, The Law of Freedom and Bondage in the United States, Boston: Little Brown \& Co, 1858-1862, II, pp. 2-150. 
tipo de organização negra que porventura surgisse. ${ }^{6}$ Além disso, todos os estados adotaram a regra de um quarto de sangue - se um dos avós fosse negro ou mulato, a pessoa seria mulata -, e todos os mulatos eram tratados da mesma forma que os negros. Libertos (mulatos ou negros) não podiam atuar como testemunhas em processos judiciais envolvendo brancos, ${ }^{7}$ eram severamente punidos por atacar brancos, e em diversos tipos de crimes eram tratados como escravos e podiam até ser chicoteados. Finalmente, como os escravos, receberiam a pena capital pelo estupro de mulher branca. ${ }^{8}$ Muitos estados exigiam a saída de escravos recém-libertos dos seus territórios, ${ }^{9}$ e a maior parte do sul e alguns estados do norte proibiam sua migração de outros estados. ${ }^{10}$ Alguns proibiram, ainda, o retorno de quaisquer libertos neles nascidos se os tivessem deixado por qualquer motivo. ${ }^{11}$ Ainda em meados do século XVIII apareceram as primeiras limitações severas à emancipação (Virgínia proibiu todas as alforrias particulares entre 1723-1759), e até mesmo a primeira de muitas proibições temporárias, mas totais, de alforria: ${ }^{12} \mathrm{e}$ todos os estados do sul, progressivamente, tornaram a concessão da liberdade mais difícil, exigindo dispendiosos processos nos tribunais, e muitos estados proibiram a qualquer proprietário conceder alforrias postmortem. ${ }^{13}$ Alguns estados, como Geórgia em 1801, Mississipi em 1805, Carolina do Sul em 1820, e Virgínia em diversos períodos, foram tão longe a ponto de exigir que somente os deputados locais pudessem aprovar qualquer ato de liberdade, subtraindo este poder totalmente das mãos dos senhores. Houve estados do sul que proibiram aos libertos até mesmo o acesso ao ensino público ou a pregar uma religião. ${ }^{14}$ Ao longo do

\footnotetext{
6 Massachusetts, 1705; Delaware, 1807; Indiana, 1817; Maine, 1821; Tennessee, 1822; Illinois, 1829; Carolina do Norte, 1830; Florida, 1832; Minnesota, 1849-50; Califórnia, 1850; Kansas, 1855; Washington territory, 1855; Novo México, 1859.

7 Carolina do Norte, 1777; Illinois, 1827; Minnesota, 1851; Oregon, 1854; Kansas, 1857.

8 Kentucky, 1793; Carolina do Norte, 1823; Virginia, 1824-25; Alabama, 1831.

9 Virginia, 1805-6; Carolina do Norte, 1830; Mississipi, 1829; Tennessee, 1831; e Iowa, em 1859 , ordenou até a expulsão de todas as pessoas de cor livres.

10 Virginia, 1793; Carolina do Sul, 1800; Maryland, 1806; Delaware, 1807; Geórgia, 1818; Mississipi, 1822; Carolina do Norte, 1826; Tennessee, 1831; Oregon, 1858; Kentucky, 1852; Indiana, 1852

11 Por exemplo, Geórgia em 1835

12 Carolina do Norte, 1777, Geórgia, 1801 e Maryland em 1860

13 Geórgia, 1849

${ }^{14}$ Geórgia, 1829; Virginia, 1830-1; Carolina do Norte, 1830, Missouri, 1847.
} 
século XIX, eles foram cada vez mais limitados na sua mobilidade profissional, com restrições às atividades econômicas que podiam desenvolver. Em 1860, a Carolina do Sul chegou a exigir que negros livres usassem distintivos gravados com seus nomes, ocupação e um número de registro. ${ }^{15}$ Ao examinar essas leis, que se tornaram cada vez mais draconianas depois de 1800, um estudioso concluiu que

os brancos tinham empurrado os negros livres para um lugar de permanente inferioridade jurídica. Como os escravos, os negros livres ficaram, em geral, sem direitos políticos, foram impossibilitados de se deslocar livremente, proibidos de depor contra os brancos, e muitas vezes foram punidos com o chicote. ${ }^{16}$

A severidade dessas leis foi reconhecida até mesmo por estudiosos norte-americanos, mas sua relevância para uma análise comparativa foi rejeitada. Os ataques, após os anos setenta, à escola comparativa vieram de acadêmicos dos Estados Unidos que, enquanto celebravam o "excepcionalismo" da história do país em outras áreas, o negaram no caso da escravidão. O trabalho de Eugene Genovese foi crucial neste contexto. Seu argumento foi de que os duros códigos legais não expressavam a verdadeira natureza do sistema escravista, que teria sido na verdade atenuado pelo paternalismo num regime que pouco se diferenciou do de outras sociedades escravistas nas Américas. ${ }^{17}$ Outros estudiosos, como C. Van Woodward, argumentariam que o crescimento demográfico natural da população escrava nos Estados Unidos, contra um decréscimo nas sociedades escravistas no resto das Américas, era clara evidência de que o tratamento dado aos escravos foi melhor nos Estados Unidos e que, portanto, as sociedades latino-americanas tiveram um sistema escravista mais severo. ${ }^{18}$

15 Hurd II, 100.

16 Ira Berlin, Slaves without Masters. The Free Negro in the Antebellum South, Nova York: WW Norton, 1974, p. 97. Para as leis pós-emancipação de Jim Crow, ver Franklin Johnson, The Development of State Legislation Concerning the Free Negro, Nova York: The Lawbook Exchange, 1916.

17 Ver Eugene Genovese, Roll, Jordan, Roll: The World the Slaves Made, Nova York: Pantheon Books, 1972, part 1. Ver também Marvin Harris, Patterns of Race in the Americas, Nova York: Walker and Co., 1964.

${ }^{18}$ C. Van Woodward, American Counterpart: Slavery and Racism in the North-South Dialogue, Boston: [s.e.], 1971. 
Mas, a existência daquelas leis nos estados do Sul deve ser explicada, e elas de fato significaram muito sobre a realidade das ideias, crenças e ações. Elas realmente tiveram um profundo impacto na definição da posição das pessoas livres negras nas sociedades americanas que emergiram da escravidão. O argumento demográfico, do melhor tratamento, desaparece quando as variações de mortalidade e fecundidade são examinadas. Ambos, brancos e negros, no resto das Américas, tiveram padrões de mortalidade e fertilidade diferentes dos norte-americanos. Ademais, a intensidade do tráfico atlântico de escravos e seu impacto sobre a idade e o sexo de africanos desembarcados, juntamente com as diferentes condições de saúde e variadas práticas de aleitamento, influenciaram a mais baixa fertilidade e a maior mortalidade dos escravos fora dos Estados Unidos, o que teve pouco a ver com o "melhor" ou "pior" tratamento da população escrava. ${ }^{19}$ A escravidão foi torpe e brutal em todas as sociedades, e o trabalho arrancado de todos os escravos em toda parte foi duro e muito mais exigente do que se exigiu de trabalhadores assalariados livres. Foi também em geral arrancado, indiscriminadamente, pelo uso de castigos corporais.

Esta falsa concentração no suposto "melhor" ou "pior" tratamento aos escravos tirou o foco das instituições e as práticas sociais e econômicas e levou a uma rejeição total da escola comparativa como um modelo viável de debate historiográfico, pelo menos na historiografia norte-americana. Exceto pelas tentativas de lidar com "comunidade escrava" numa perspectiva comparativa, ${ }^{20}$ há poucas novas discussões sobre este tema, com a assunção pela maioria dos estudiosos na América do Norte de que todos os sistemas escravistas foram iguais e que, de algum modo, os latino-americanos foram "piores". ${ }^{21}$

19 Ver Herbert S. Klein e Stanley Engerman, "Fertility Differentials between Slaves in the United States and the British West Indies: A Note on Lactation Practices and their Implications", William and Mary Quarterly, v. XXXV, n. 2 (1978), pp. 357-74.

20 Ver, por exemplo, Peter Kolchin, Unfree Labor: American Slavery and Russian Serfdom, Cambridge, Mass: Harvard University Press, 1987.

${ }^{21}$ Era a posição de Comer Van Woodward, Eugene Genovese, Marvin Harris e outros que têm dominado a historiografia dos Estados Unidos desde então. Um recente revisão desse debate é encontrada em Alejandro de la Fuente, "Slave Law and Claims-Making in Cuba: The Tannenbaum Debate Revisited", Law and History Review, v. 22, n. 2 (2012), pp. 339-69 Os únicos norteamericanos a investigar a escravidão comparativamente desde os anos 1970 são Laird W. Bergad, 
Eu argumentaria que, de fato, existiram importantes diferenças entre os regimes escravistas nas Américas, e essas diferenças tiveram importantes consequências sociais, econômicas e políticas para as populações afro-americanas. Vamos iniciar esta análise comparativa examinando o que é semelhante em todos eles. Para começar, quase todos os principais sistemas escravistas criados nas Américas tiveram a mesma finalidade econômica. Num mundo onde a terra era barata e o trabalho era caro, e para onde o trabalhador europeu não se sentiu atraído pela realidade salarial americana, os africanos foram utilizados como a alternativa mais barata de força de trabalho. Mas, devido ao seu ainda elevado custo, os africanos eram geralmente associados, na maioria dos casos, aos setores mais avançados de exportação, produzindo, nas sociedades em pauta, para um mercado mundial. A única variação importante nesse modelo foi a escravidão mais doméstica e urbana praticada pelos espanhóis nas regiões fortemente ameríndias, onde os africanos ficaram concentrados no serviço doméstico, e a produção artesanal de bens para consumo e a exportação era feita pelos indígenas. Escravos africanos foram usados em algumas atividades mineradoras, na maioria ouro e cobre, mas em geral as minas de prata foram tocadas, exclusivamente, com o trabalho indígena.

Com exceção do Caribe inglês e das Antilhas francesas, quase todas as principais sociedades escravistas pareciam iguais, com cerca de um terço de sua população constituída por escravos e outro terço por pessoas livres que possuíam escravos. Embora a maioria dos senhores tivesse apenas um escravo, a norma da propriedade escravista era da

The Comparative Histories of Slavery in Brazil, Cuba, and the United States, Nova York: Cambridge University Press, 2007; e Herbert S. Klein e Ben Vinson III, African Slavery in Latin America and the Caribbean, Nova York: Oxford University Press, 2007, e todos estes autores focam o tema pelas lentes da pesquisa latino-americana. Isso não significa que outros não estejam a estudar a escravidão a partir de uma perspectiva comparativa. Os brasileiros têm recentemente elaborado a maioria dos trabalhos com esse enfoque. Ver, por exemplo, Célia Maria Marinho de Azevedo, Abolicionismo: Estados Unidos e Brasil, uma história comparada: século XIX. São Paulo: Annablume, 2003; Keila Grinberg. "Freedom Suits and Civil Law in Brazil and the United States", Slavery \& Abolition, v. 22, n. 3 (2001), pp. 66-82; Rafael de Bivar Marquese, Feitores do corpo, missionários da mente: senhores, letrados e o controle dos escravos nas Américas, 1660-1860, São Paulo: Companhia das Letras, 2004; Mariana L. R. Dantas, Black Townsmen: Urban Slavery and Freedom in the EighteenthCentury Americas, Nova York: Palgrave Macmillan, 2008; e Rafael de Bivar Marquese, Támis P. Parron e Márcia Regina Berbel, Escravidão e política. Brasil e Cuba, c.1790-1850, São Paulo: Hucitec, 2010. 
ordem de cinco a dez escravos por proprietário, e seu tamanho médio no setor agrícola-exportador era de aproximadamente 50 a100 escravos. Foram as ilhas açucareiras não-hispânicas que se destacaram como diferentes, com uma maioria da sua população escravizada em propriedades agrícolas com várias centenas de escravos. ${ }^{22}$

Mas houve pouca diferença na organização do trabalho escravo nas lavouras de exportação. Todas elas, independentemente do seu produto ou tamanho, organizaram o trabalho de forma semelhante. Os trabalhadores eram agrupados com base na idade e capacidade física, independentemente do sexo. Esses grupos de trabalho rural eram supervisionados por feitores que administravam as tarefas rotineiras com o uso de chicotes, criando as chamadas "fábricas no campo", um tipo próprio de organização do trabalho. Nesses grupos, mulheres e homens, igualmente, executavam as tarefas básicas do plantio, manutenção e colheita das culturas. Além do campo, todos tinham algum trabalho a fazer alhures, não importando a idade ou o sexo. Esses sistemas de trabalho escravo foram incomuns, com uma população economicamente ativa maior do que todas as populações trabalhadoras da época, na ordem de $80 \%$ de todos os escravos ocupados todo o tempo em alguma função econômica, em comparação com os cerca de 50-60\% entre a maioria dos camponeses das sociedades de então. ${ }^{23}$

Havia, é claro, diferenças nos regimes agrícolas baseadas na tecnologia de produção. $\mathrm{O}$ açúcar teve um regime de trabalho mais duro para os escravos do que o café, as lavouras que tinham três safras anuais

${ }^{22}$ Ver o sugestivo ensaio de Stuart B. Schwartz, "Patterns of Slaveholding in the Americas: New Evidence from Brazil", The American Historical Review, v. 87, n. 1 (1982), pp. 55-86.

23 Ver, por exemplo, Robert William Fogel e Stanley L. Engerman, Time on the Cross: The Economics of American Negro Slavery, Boston: Little, Brown and Company, 1974; Gabriel Debien, Les esclaves aux Antilles françaises, Basse-Terre \& Fort-de-France: Societies d'historie de la Guadeloupe and Martinique, 1974; Michael Craton, Sinews of Empire: A Short History of British Slavery, Nova York: Doubleday, 1974; Barry W. Higman, Slave Population and Economy in Jamaica, 1807-1834, Cambridge: Cambridge University Press, 1976, e Slave Population of the British Carribean, 1807-1834, Baltimore: Johns Hopkins University Press, 1984; Manuel Moreno Fraginals, El ingenio: complejo económico social cubano del azúcar, Havana: Editorial de Ciencias Sociales, 1978; Francisco Vidal Luna e Herbert S. Klein, Slavery and the Economy of São Paulo, 1750-1850, Stanford: Stanford University Press, 2003; e Laird W. Bergad, Slavery and the Demographic and Economic History of Minas Gerais, Brazil, 1720-1888, Nova York: Cambridge University Press, 1999 
exigiam mais trabalho do que aquelas que tinham duas ou menos, e assim por diante. Algumas culturas, como o açúcar, necessitavam de uma grande quantidade de trabalho técnico e outras, como o tabaco e o café, demandavam poucas tarefas especializadas para chegar ao produto final, e isso influenciaria os níveis relativos de qualificação na população escrava. Todos os regimes tenderam a reservar o trabalho qualificado nas plantações para os escravos do sexo masculino, embora no trabalho fora das plantações as mulheres escravas realizassem uma grande variedade de atividades qualificadas, sendo especialmente importantes no setor têxtil e no comércio. Esses regimes de trabalho servil rural, portanto, compartilham características comuns em todas as sociedades, e um viajante do século XIX teria notado pouca diferença, exceto nas rotinas de execução das tarefas, nas plantações de qualquer lugar nas Américas.

Embora o trabalho em grupo e a disciplina dos escravos fossem semelhantes em toda parte, há ainda algumas importantes diferenças econômicas entre esses regimes escravistas. O nível de habilidade e a disponibilidade de tais ocupações qualificadas para os escravos muitas vezes dependia da relativa escassez ou da oferta da mão de obra branca ou indígena. Se os negros e os mulatos, livres e cativos, fossem maioria entre trabalhadores em uma dada sociedade, eram frequentemente melhor treinados para as tarefas que exigiam habilidades, do que nas sociedades onde havia a concorrência de artesãos brancos. Nessas sociedades, que não tinham a concorrência de grandes grupos de trabalhadores brancos, índios ou mestiços livres, e que podiam importar um grande número de africanos, era mais comum encontrar escravos em muito mais ocupações do que naquelas em que havia mais competição de trabalho não-negro. $\mathrm{O}$ Brasil, é claro, destaca-se como um ótimo exemplo onde os cativos podiam ser encontrados em praticamente todas as ocupações e em todos os níveis de habilidade. Havia até escravos marinheiros afro-brasileiros e africanos nas tripulações de navios indo para a África para adquirir escravos. ${ }^{24}$

${ }^{24}$ Ver Herbert S. Klein, The Middle Passage: Comparative Studies in the Atlantic Slave Trade, Princeton: Princeton University Press, 1978, cap. 3; Jaime Rodrigues, De costa a costa: escravos, marinheiros e intermediários do tráfico negreiro de Angola ao Rio de Janeiro, 17801860, São Paulo: Companhia das Letras, 2005; e João José Reis, Flávio dos Santos Gomes e Marcus J. M. de Carvalho, O Alufá Rufino: tráfico, escravidão e liberdade no Atlântico Negro (c. 1822-C. 1853), São Paulo: Companhia das Letras, 2010. 
Mas em todos os centros urbanos da América Latina, desde o século XVI até o início do XIX, afro-latino-americanos encontravam-se bem representados na maioria dos principais ofícios e, embora provavelmente estivessem mais propensos a serem aprendizes e diaristas do que os trabalhadores brancos, eles foram também considerados mestres em muitos ofícios. ${ }^{25}$

Tão importante quanto o capital humano envolvido nesses ofícios, era a necessidade dos donos de escravos de oferecer recompensas para obter um bom serviço. Como vários estudos da escravidão moderna e clássica têm mostrado, o trabalho não qualificado era rotineiro e controlado pela força, de modo a produzir ganhos com relativa eficiência. Mas o trabalho especializado não pode ser rotinizado e nem o trabalhador chicoteado para ser obediente. ${ }^{26}$ Assim, em Minas Gerais, escravos mineiros itinerantes, que trabalhavam sozinhos à procura de aluviões de ouro, foram pagos nesse metal e autorizados a comprar sua liberdade, enquanto os escravos utilizados nas conhecidas jazidas operadas por sistemas hidráulicos trabalhavam em grupos e não recebiam qualquer tipo de incentivos.

Esta abertura do mercado de trabalho para escravos e pessoas livres de cor faz uma diferença crucial no funcionamento de regimes escravistas, uma vez que em um país como o Brasil, por exemplo, apenas cerca de um terço dos escravos estavam nas fazendas e engenhos, de acordo com o primeiro censo nacional de 1872, enquanto a maioria se encontrava em atividades variadas, de trabalho urbano não qualificado à produção agrícola rural, do transporte de mulas à pesca de baleia. ${ }^{27}$ Muitos trabalhavam em unidades familiares, com as famílias dos pró-

${ }^{25}$ Sobre atividades artesanais urbanas, por exemplo, um dos melhores estudos é encontrado em Frederick P. Bowser, The African Slave in Colonial Peru, 1524-1650, Stanford: Stanford University Press, 1974. Para algumas dessas atividades urbanas para pessoas de cor livres em Cuba, ver Herbert S. Klein, Slavery in the Americas. A Comparative History of Cuba and Virginia, Chicago: University of Chicago Press, 1967, capítulo 9.

26 Ver Stefano Fenoaltea, "Slavery and Supervision in Comparative Perspective: A Model", The Journal of Economic History, v. 44, n. 3 (1984), pp. 635-68. Também usando esse modelo, Flávio Rabelo Versiani, "Escravidão "suave" no Brasil: Gilberto Freyre tinha razão?", Revista de Economia Política, v. 27, n. 2 (2007), pp. 163-83.

27 Herbert S. Klein e Francisco Vidal Luna, Slavery in Brazil, Cambridge: Cambridge University Press, 2009, capítulo 6. 
prios senhores, ou ao lado de lavradores livres. Esse mesmo modelo também podia ser encontrado em Cuba e Porto Rico. ${ }^{28}$ Tudo isso contribuiu para um mercado de trabalho mais complexo do que na América do Norte. Embora os escravos rurais permanecessem relativamente isolados, em qualquer outro setor trabalhadores escravizados podiam ser encontrados misturando-se com trabalhadores livres negros, branco, índios e mestiços. Assim, a importância relativa do trabalho escravo rural e urbano é tão relevante na determinação do uso ocupacional destinado aos escravos quanto o é o trabalho, agrícola ou não, na determinação dos tipos de ocupação na zona rural. Em termos de emprego do trabalho escravo e de concentração na grande lavoura, os Estados Unidos eram mais parecidos com o Caribe não-hispânico do que com os outros regimes escravistas do continente americano e das ilhas hispânicas. ${ }^{29}$

Os escravos eram utilizados em todas as tarefas imagináveis e necessárias para o funcionamento dessas sociedades. Eles eram, em grande número, alugados, empregados como aprendizes, e tinham até mesmo permissão para viver por conta própria. Embora o aluguel de escravos e a escravidão urbana existissem nos Estados Unidos, ocorreram em menor escala do que na maioria dos países latino-americanos, e tornaram-se progressivamente mais reduzidos ao longo do tempo. Além disso, enquanto nos Estados Unidos o controle do governo e dos senhores sobre os escravos urbanos tornou-se cada vez mais rigoroso no século XIX, parecia ficar cada vez mais frouxo na América Latina como o passar do tempo. Os governos municipais na América Latina estavam sempre reclamando da negligência dos senhores urbanos em disciplinar, abrigar e alimentar seus escravos, mas pouco foi feito para controlá-los. ${ }^{30}$ Em contraste, na

${ }^{28}$ Franklin W. Knight, Slave Society in Cuba during the Nineteenth Century, Madison: University of Wisconsin Press, 1970; Laird W. Bergad, Cuban Rural Society in the Nineteenth Century: The Social and Economic History of Monoculture in Matanzas, Princeton: Princeton University Press, 1990; Francisco A. Scarano, Sugar and Slavery in Puerto Rico: The Plantation Economy of Ponce, 1800-1850, Madison, Wisconsin: University of Wisconsin Press, 1984.

29 Em 1860 em torno de 52\% dos escravos no sul dos Estados Unidos estavam em escravarias de 20 ou mais indivíduos. Estas unidades teriam sido plantations e, muito provavelmente os escravos mantidos em unidades menores também foram envolvidos com a produção agrícola comercial. Luis Cecil Gray, History of Agriculture in the Southern United States to 1860, Glouster: Peter Smith, reimpresso em 1958, v. I, p. 530, Tabela 10.

30 Ver Bowser, The African Slave in Colonial Peru; e Mary C. Karasch, Slave Life in Rio de Janeiro, 1808-1850, Princeton: Princeton University Press, 1987. 
América do Norte oitocentista houve um controle eficaz e crescente do Estado sobre a vida dos escravos urbanos, que ficaram restritos a morar nas casas de seus senhores. ${ }^{31}$ Essas mudanças não estiveram relacionadas com eficiência econômica. De fato, economicamente, era mais eficaz permitir ao trabalho escravo na cidade a maior mobilidade possível para que fosse rentável. Permitir aos escravos fazer contratos, organizar as próprias moradias, o vestuário e os alimentos, reduzia os custos de manutenção para os proprietários. Reduzir o espaço de manobra dos proprietários, aumentar as suas despesas de manutenção, tudo em nome da segurança, foi de fato uma má política econômica. Invertendo o modelo de Elkins, que fala da "dinâmica do capitalismo sem oposição" nos Estados Unidos, poderíamos dizer que Brasil e Cuba foram as verdadeiras sociedades capitalistas, e que os Estados Unidos estavam dispostos a sacrificar a racionalidade econômica a outros fins preferenciais, neste caso, controle social.

Como o Estado e suas leis responderam a essas emergentes e diferentes realidades americanas? Todos os sistemas legais escravistas têm muito em comum. Como Orlando Patterson demonstrou, todos eles têm que legalmente destruir os direitos dos escravos para que estes sejam economicamente "móveis": em toda parte, os senhores puderam disciplinar seus escravos, usá-los em qualquer ocupação que quisessem, e vendê-los a alguém. Em todos os casos, os seus direitos como senhores eram apoiados pelo Estado. ${ }^{32}$ No entanto, quando chegou o século XIX, algumas diferenças emergiram nos regimes escravistas americanos. A maioria dessas diferenças desenvolveu-se a partir de práticas consuetudinárias que alteraram os direitos dos proprietários de escravos. Se os escravos vivessem por conta própria e provessem seus senhores com uma renda, tinham que fazer contratos e cuidar de suas próprias finanças. Embora como escravos não pudessem, legalmente, ter propriedade ou fazer contratos, os escravos urbanos - e, mesmo em

31 Richard C. Wade, Slavery in the Cities; the South, 1820-1860, Nova York: Oxford University Press, 1964, Claudia Goldin, Urban Slavery in the American South, 1820-1860, Chicago: University of Chicago Press, 1976.

32 Orlando Patterson, Slavery and Social Death: A Comparative Study, Cambridge: Harvard University Press, 1982. 
menor número, também do campo -, de fato, tenderam a ter propriedades e a fazer contratos independentemente de seus senhores. Em todas as propriedades rurais, escravos produziam muito dos seus próprios alimentos e, com frequência, vendiam para ambulantes que circulavam em torno das fazendas e engenhos - uma questão bastante comentada acerca de Cuba. Assim, escravos vendiam alimentos e outros bens que produziam nos seus próprios lotes, embora não tivessem direitos legais para fazê-lo. Na verdade, se não de direito, estas hortas eram muitas vezes consideradas propriedade dos escravos que as cultivavam. Escravos que possuíam propriedades ou poupança logo seriam autorizados pelo Estado a comprar a liberdade, um sistema que evoluiu do direito consuetudinário para logo se tornar plenamente elaborado nos códigos escravistas locais. No Brasil e em Cuba, a compra da própria alforria era um ato comum que, com o tempo, ganhou suporte legal. A partir de 1871, com a chamada Lei do Ventre Livre, o escravo no Brasil podia comprar sua alforria, mesmo contra a vontade do senhor, e foi autorizado a acumular dinheiro para tal. Este foi o caminho principal para a liberdade de escravos africanos e crioulos, e a compra da própria alforria representou cerca de um terço de todas as alforrias. ${ }^{33}$ A alforria também foi facilitada por vários meios legais, desde testamentos e legados, reconhecimento de paternidade na pia batismal, a cartas formais de liberdade, e foi considerada uma parte normal do sistema escravista nessas sociedades. ${ }^{34}$

${ }^{33}$ Uma das principais pesquisas sobre alforrias concluiu que os africanos estavam sobre-representados nas pagas e sub-representados nas gratuitas. Ver Eduardo França Paiva, Escravidão e universo cultural na colônia: Minas Gerais, 1716-1789, Belo Horizonte: UFMG, 2001, p. 181. Uma pequena amostra das cidades baianas de Salvador e Santo Amaro no século XIX também apresentou este mesmo modelo de sobre-representação africana entre os libertos que pagaram por suas alforrias, e de pardos entre as gratuitas. Ver Arnold Kessler, "Bahian Manumission Practices in the Early 19th Century", Comunicação apresentada na American Historical Association, em 29 de dezembro de 1973, Tabela IX, pp. 19-20. Um recente estudo de 4.566 alforrias em São João Del Rei, para o período entre 1774/1848, encontrou que para $44 \%$ dos escravos crioulos alforriados a liberdade fora mediante pagamento, comparados a $76 \%$ dos africanos que compraram sua liberdade. Sheila de Castro Faria, "Aspectos demográficos da alforria no Rio de Janeiro e em São João Del Rey entre 1700 e 1850”, XVI Encontro Nacional de Estudos Populacionais, ABEP, 2008, quadro 7, p. 10.

34 Agostinho Perdigão Malheiro, A escravidão no Brasil, 2 vs. Rio de Janeiro: Typografia Nacional, 1866; Stuart B. Schwartz, "The Manumission of Slaves in Colonial Brazil: Bahia, 16841745", The Hispanic American Historical Review, v. 54, n. 4 (1974), pp. 603-35; Mieko Nishida, "Manumission and Ethnicity in Urban Slavery: Salvador, Brazil, 1808-1888", The Hispanic American Historical Review, v. 73, n. 3 (1993), pp. 361-91; Ortiz, Hampa afro-cubana, pp.285-90; 
Parece que, no século XVIII, todos os sistemas escravistas nas Américas produziram aproximadamente a mesma proporção de escravos alforriados. Em todas as sociedades, pais libertaram filhos e parceiros afetivos escravizados, e senhores, por razões religiosas ou morais, libertaram escravos, pois a lealdade, muitas vezes, era recompensada com a alforria. A compra da própria alforria se verificou em todos os regimes escravistas. Tudo isso começou num ritmo lento e produziu uma modestamente crescente classe de pessoas de cor livres. Mas, no século XIX, algumas sociedades escravistas começaram a fechar esses caminhos para a alforria, enquanto outras progressivamente ampliaram o direito de compra e incentivaram outros processos de alforria. As leis e os tribunais aceitaram todos esses procedimentos de alforria e os protegeram. Por sua vez, em alguns lugares, esses incentivos legais para a alforria levaram a uma expansão cada vez mais rápida da população de cor livre, que logo excedeu a de escravos no século XIX. Até o primeiro censo nacional do Brasil, em 1872, dezesseis anos antes da Abolição, por exemplo, havia 4,2 milhões negros e mestiços livres e apenas 1,5 milhões de escravos. Para os Estados Unidos em 1860, os valores foram invertidos - com quase quatro milhões de escravos e menos de meio milhão dos livres de cor. Em nenhuma outra importante sociedade escravista foram eles tão numerosos e tão importantes quanto no Brasil. Mas, em todo o mundo ibero-americano, na primeira parte do século

Norman A. Meiklejohn, "The Implementation of Slave Legislation in Eighteenth-Century New Granada”, in Robert Toplin (org.), Slavery and Race Relations in Latin America (Westport: Greenwood Press,1974), pp. 176-203. Muitos estudos sobre alforria de escravos na pia batismal mostram que cerca de $2 \%$ dos escravos nascidos eram registrados como pessoas livres, com predominância de meninas. Ver James Patrick Kiernan, "Baptism and Manumission in Brazil: Paraty, 1789-1822”, Social Science History, v. 3, n. 1 (1978), pp. 56-71; Cristiano Lima da Silva, "As alforrias nos registros de batismos da matriz de Nossa Senhora do Pilar de São João Del-Rei: uma análise demográfica (1751-1850)", Anais do $2^{\circ}$ seminário regional do CEO - Centro de Estudos do Oitocentos (Juiz de Fora: Clio Edições Eletrônicas, 2005), Tabela 1; Cristiano Lima da Silva, "Senhores e pais: reconhecimento de paternidade dos alforriados na pia batismal na Freguesia de Nossa Senhora do Pilar de São João del-Rei (1770-1850)", Anais do I Colóquio dos LAHES - Laboratório de Historia Econômica e Social (Juiz de Fora, 2005); Rômulo Andrade, "Ampliando estudos sobre famílias escravas no século XIX (crianças cativas em Minas Gerias: legitimidade, alforria e estabilidade familial)", Revista Universidade Rural, Série Ciências Humanas, v. 24, n. 1-2 (2002), pp. 101-13; Miriam Moura Lott, "A lista nominativa de 1838, características demográficas, econômicas e sociais de Ouro Preto", Anais do XIII Seminário sobre a Economia Mineira (2008). 
XIX, eles ou se igualaram em número aos escravos ou rapidamente ultrapassaram-nos em importância. Nada disso aconteceu nas nações e colônias francesas ou inglesas. ${ }^{35}$

Na América do Norte, a legislação do século XIX progressivamente restringiu esse processo de alforria e tentou isolar, e até mesmo expulsar, os negros e mulatos livres e libertos de seus territórios. Senhores foram progressivamente restringidos no seu direito de alforriar escravos dentro das fronteiras americanas, nenhuma sustentação legal foi dada aos acordos de compra de alforria, e para os afro-americanos livres havia cada vez mais restrições, e até a mobilidade física foi cerceada.$^{36}$ Essa legislação foi bem-sucedida, e essa população foi mantida numa proporção baixa em relação ao que era antes de 1860. Além disso, mais da metade dessas pessoas viviam fora dos estados escravistas do sul. Estima-se que em 1860, apenas 3\% da população livre nos estados do sul eram negros e mulatos libertos ou livres. ${ }^{37}$ Esse medo crescente de alforria, que foi dominante nos Estados Unidos, no século XIX, tem, até agora, recebido pouca atenção e vale a pena ser estudado. Já se sugeriu que essa hostilidade em relação aos libertos era vista como um reforço à legitimidade do sistema escravista pelos agricultores norteamericanos, que foram aos poucos elaborando a defesa da escravidão como única condição adequada para afro-americanos. Por que outras sociedades escravistas não perceberam isso da mesma maneira? Por que uma grande e emergente classe de cor livre na América Latina não ameaçou as tradicionais relações senhor - escravo?

Uma grande parte dessa diferença de atitudes para com os libertos pode ser vista também nos diferentes papeis político, econômico e social das pessoas de cor livres em cada uma das sociedades escravistas. Uma vez livres, os afro-americanos desempenharam papeis muito mais importantes em suas respectivas sociedades latino-americanas do que nas nações e colônias inglesas. Tanto na América espanhola quanto

35 Ver tabelas anexas em Klein e Vinson, African Slavery.

36 Sobre as dificuldades na compra de alforrias nos Estados Unidos, ver Sumner Eliot Matison, "Manumission by Purchase", The Journal of Negro History, v. 33, n. 2 (1948), pp. 146-67.

37 Lewis Cecil Gray, History of Agriculture in the Southern United States to1860, Washington: Carnegie Institution, 1932, v. I, pp. 481-82. 
na portuguesa (e depois no Brasil independente) organizaram a população negra e mestiça em unidades militares coloniais e usaram-na para lutar em guerras internacionais e rebeliões internas. Na América espanhola, os índios foram proibidos de servir na milícia, mas unidades de mulatos e negros foram organizadas e desempenharam papel respeitável. Em muitos casos, essas tropas foram usadas, mesmo fora de seus territórios de origem, pelos governos imperiais. No caso do Brasil, as unidades de pardos e pretos eram a norma até 1830, e, mesmo após a criação de uma Guarda Nacional unificada sob o Império, os negros foram vitais dentro da instituição militar, a exemplo dos Voluntários da Pátria (também conhecidos como Zuavos Negros) na Guerra do Paraguai, em meados da década de 1860. Assim, em toda a parte, aos homens de cor livre foi concedido o direito de portar armas, e eles usaramno para ampliar seus próprios direitos particulares. Em todos os países os milicianos tinham acesso privilegiado a tribunais militares, e no México eles conseguiram escapar de impostos cobrados especificamente aos afro-mexicanos livres, assim como aos índios. Ao mesmo tempo, uma elite de homens dessa classe adquiriu poder como oficiais nessas unidades. Isso não quer dizer que esses militares não tivessem sido discriminados em termos de postos no exército ou na execução das piores tarefas. Mas, é claro que eles representavam uma parte importante do aparelho de Estado desde o início da escravidão. ${ }^{38} \mathrm{Na}$ verdade, muitos dos líderes revolucionários dos movimentos de independência, no início e fim do século XIX, em países como México e Cuba vieram dessa classe.

A população afro livre na América Latina teve poucos obstáculos à sua mobilidade geográfica, os mesmos que todas as pessoas livres

38 Entre outros estudos, ver Herbert S. Klein “The Colored Militia of Cuba, 1568-1868”, Caribbean Studies, v. VI, n. 2 (1966), pp. 17-27; Ben Vinson III, Bearing Arms for His Majesty: The Freecolored Militia in Colonial Mexico, Stanford: Stanford University Press, 2001; Hendrik Kraay, Race, State and Armed Forces in Independence-Era Brazil: Bahia, 1790s-1840s, Stanford: Stanford University Press, 2001; Joseph P. Sanchez, "African Freedmen and the Fuero Milita: A Historical Overview of Pardo and Moreno Militiamen in the Late Spanish Empire", Colonial Latin American Historical Review v. 3, n. 2 (1994), pp.165-84; Alan Kuethe, "The Status of the Free-Pardo in the Disciplined Militia of New Granada", Journal of Negro History, v. 56, n. 2 (1971), pp. 105-17; e o número especial sobre esse assunto organizado por Ben Vinson III e Stewart King do Journal of Colonialism and Colonial History, v. 5, n. 2 (2004). Sobre a experiência francesa, ver Stewart R. King, Blue Coat or Powdered Wig? Free People of Color in Pre-Revolutionary Saint-Domingue, Athens, Geórgia: University of Georgia Press, 2001. 
dentro de suas sociedades. No Brasil, deslocaram-se livremente entre áreas urbanas e rurais, e de província para província, como evidenciado pelos registros judiciais da época. As restrições draconianas à mobilidade geográfica desenvolvidas na América do Norte no século XIX não ocorreram na América Latina. Aqui as pessoas livres, independentemente da cor, podiam morar em qualquer lugar em que pudessem se dar ao luxo de viver. Estudos sobre padrões residenciais, em cidades como México e San Juan de Porto Rico, também têm demonstrado que negros livres moravam ao lado e, muitas vezes, misturados com famílias de brancos e mestiços, e era tão comum para eles alugar cômodos em suas casas para brancos, como era, muitas vezes, para os brancos alugar quartos para eles. ${ }^{39}$ Embora os guetos urbanos dos Estados Unidos sejam usualmente tidos como originários da era pós-abolição, é, no entanto, revelador que nenhuma mistura sistemática de raças em moradias individuais tivesse sido apontada nos Estados Unidos. ${ }^{40}$

Todas as ocupações estavam abertas à população de cor livre, à exceção daquelas tipicamente da elite, e mesmo as restrições a estas diminuíram ao longo do período colonial e foram totalmente eliminadas no século XIX nas repúblicas latino-americanas. De Lima à Cidade do México, há inúmeros exemplos de pessoas dessas camadas que obtiveram autorização régia para se estabelecer em ocupações de elite que lhes eram oficialmente negadas. Isso incluía desde posições no governo e na Igreja, até ofícios mecânicos a elas vetados por lei.

Uma minoria das pessoas negras e mestiças livres até possuía escravos, um fenômeno que ocorreu em todas as sociedades escravistas, incluindo os Estados Unidos. ${ }^{41}$ No caso do Brasil, onde esses se-

39 Ver por exemplo, R. Douglas Cope, The Limits of Racial Domination: Plebeian Society in Colonial Mexico City, 1660-1720, Madison: University of Wisconsin Press, 1994; e Jay Kinsbruner, Not of Pure Blood: The Free People of Color and Racial Prejudice In Nineteenthcentury Puerto Rico, Durham: Duke University Press, 1996.

40 Ver David M Cutler, Edward L. Glaeser e Jacob L. Vigdor, "The Rise and Decline of the American Ghetto", Journal of Political Economy, v.107, n. 3 (1999), pp. 455-506.

${ }^{41}$ Sobre as poucas centenas de pessoas de cor livres que possuíam escravos, ver o estudo clássico de Carter G. Woodson, Free Negro Owners of Slaves in the United States in 1830, Nova York: Association for the Study of Negro Life and History, 1924. Para uma atualização do estudo de Woodson sobre um estado em particular, ver Leonard Koger, Black Slave Owners: Free Black Slave Masters in South Carolina, 1790-1860, Jefferson: McFarland, 1985. 
nhores pardos e negros têm sido bem estudados, eles representavam uma significativa minoria entre os proprietários de escravos, na maior parte das regiões, e eram em sua maioria artesãos trabalhando em pequenas oficinas. Neste contexto, as mulheres eram um protagonista muito significativo entre esses proprietários de escravos. Nos Estados Unidos eles representavam uma proporção muito menor dos proprietários de escravos do que no Brasil. ${ }^{42}$

Os escravos e as pessoas de cor livres e libertas, nas áreas rurais e urbanas da América Latina, se misturavam mais ou menos livremente com os brancos. Embora a maioria das manifestações religiosas africanas, como o candomblé e a santeria, fossem semiclandestinas no período escravista e muitas vezes violentamente reprimidas, havia inúmeras festividades e outras manifestações públicas onde negros e brancos se misturavam, e encontramos até escravos aparecendo nesses locais. Os registros judiciais da América Latina estão cheios de escravos que conviviam com os brancos e pessoas de cor livre nas numerosas tabernas, que eram importantes locais de sociabilidade. Há também numerosos casos de escravos fugindo para as cidades para viver como livre, embora também acontecesse que gente negra livre ou liberta fosse frequentemente tomada por escravo e como tal perseguida e presa.

42 Para estudos recentes mostrando a importância relativa das pessoas livres de cor como proprietários de escravos em vários municípios do Brasil, ver, para a província de São Paulo, os dois estudos de Francisco Vidal Luna, Minas Gerais: escravos e senhores, São Paulo: IPE/USP, 1981, e "São Paulo: população, atividades e posse de escravos em vinte e cinco localidades (17771829)", Estudos Econômicos v. 28, n. 1 (1998), pp. 99-169; e Francisco Vidal Luna e Herbert S. Klein, "Slaves and Masters in Early Nineteenth-Century Brazil: São Paulo", Journal of Interdisciplinary History, v. 21, n. 4 (1991), pp. 549-73, e mais recentemente, Francisco Vidal Luna e Herbert S. Klein, Slavery and the Economy of São Paulo, 1750-1850, Stanford: Stanford University Press, 2003. Para Minas Gerais, ver Herbert S. Klein e Clotilde Andrade Paiva, "Free Persons in a Slave Economy, Minas Gerais in 1831", Journal of Social History, v. 29, n. 4 (1996), pp. 933-62; Clotilde Andrade Paiva e Herbert S. Klein, "Slave and Free in Nineteenth-Century Minas Gerais: Campanha in 1831", Slavery \& Abolition v. 15, n. 1 (1994)”, pp.1-21, e sobre a comparação entre duas províncias, Francisco Vidal Luna e Herbert S. Klein, "Free Colored in a Slave Economy: The Case of São Paulo and Minas Gerais, 1829-1830", Hispanic American Historical Review, v. 80, n. 4 (2000), pp. 913-41. Para estudos sobre dois municípios na Bahia, ver B. J. Barickman, "As cores do escravismo: escravistas 'pretos', 'pardos' e 'cabras' no Recôncavo baiano, 1835", População e Família v. 2, n. 2 (1999), pp.7-62. Um estudo detalhado de testamentos de libertos, no século XIX na Bahia, mostra que existe uma grande correlação entre riqueza e propriedade escrava - com praticamente todos os libertos mais ricos possuindo escravos, e quanto mais ricos fossem maior número de escravos tinham. Maria Inês Cortes de Oliveira, $O$ liberto: o seu mundo e os outros, Salvador, 1790 -1890, São Paulo: Corrupio, 1988, p. 38. 
Embora tenha sido sugerido que as rebeliões de escravos foram mais numerosas e mais violentas na América Latina do que na América do Norte, estes eventos foram poucos e distantes uns dos outros na maioria das sociedades escravistas. Além disso, escravos fugitivos eram comuns em todos os regimes escravistas. Mas, no que as sociedades da América Latina, e até mesmo do Caribe, diferem da América do Norte é no tamanho e extraordinário número de quilombos, nas primeiras, e sua escassez nesta última. O mapa do Brasil está repleto de dezenas de locais chamados quilombo, e as comunidades de cimarones, por toda a América espanhola e ilhas do Caribe, foram muito importantes e numerosas. As causas para a importância relativa dessas comunidades fora da América do Norte foram principalmente as condições ecológicas, tais como terrenos montanhosos com vegetação tropical e semitropical, onde comunidades isoladas podiam se manter com sucesso. Também o constante desaparecimento de escravos no seio da população negra livre era muito mais comum na América Latina do que na América do Norte, devido à existência, naquela, de grandes afro-comunidades livres, e de mais centros urbanos, que deram cobertura significativa aos escravos fugidos. Além disso, uma vez estabelecidas ao longo de várias gerações, a maioria dos quilombos, de fato, converteram-se em comunidades agrícolas autônomas e se tornaram parte da paisagem do mundo rural livre.

Possivelmente devido à sua importância econômica, ou a sua incapacidade de influenciar seriamente a política das elites, aos negros e mestiços livres fosse oferecida uma ampla gama de direitos que lhes foram negados na América do Norte. Eles podiam votar - mas no Brasil somente se nascidos ali, e não na África - se tivessem renda ou propriedade que os qualificasse para tal, portar armas, viver onde pudessem encontrar trabalho e moradia e, por volta do século XIX, tiveram poucas restrições em suas profissões ou oportunidades educacionais. Embora o Estado tivesse às vezes tratado mais duramente os negros e pardos livres do que seus pares mestiços e brancos, eles, no entanto, foram tratados de forma bastante diferente de seus irmãos escravos. ${ }^{43}$ Eles podiam comparecer diante de um tribunal, como testemunhas e como

43 Ver por exemplo, Leila Mezan Algranti, O feitor ausente: estudos sobre a escravidão urbana no Rio de Janeiro, 1808-1822, Petrópolis: Vozes, 1988. 
querelantes, e fazer contratos legais. Como Tannenbaum costumava dizer, eles foram "cidadãos" em todos os países, formados ao longo do Oitocentos, em que viveram. ${ }^{44}$

Isso não quer dizer que negros e mestiços fossem iguais aos brancos, ou que não existisse qualquer tipo de discriminação dos que nasceram livres em relação àqueles que foram libertados ao longo de suas vidas e seus descendentes. A imensa maioria dos negros libertos saiu da escravidão sem uma poupança, e levou consigo somente o capital humano em termos de conhecimento, idiomas e habilidades para o traba1ho. Assim, formaram a base da camada de pobres em todas as sociedades latino-americanas, posição que compartilharam com uma minoria de brancos empobrecidos e mestiços. Tem sido sugerido, em estudos sobre a Cidade do México, por exemplo, que a discriminação entre os pobres era bastante limitada e a cor uma marca muito fluida que podia mudar no decorrer de uma vida. Para aqueles que subiam na escala econômica e social, a discriminação claramente se acentuava tanto quanto mais alto subissem. ${ }^{45}$ Os casos de filhos processando pais pelo direito de casar, no final do século XVIII, na América espanhola, mostram que os brancos que ocupavam uma posição intermediária na sociedade foram altamente discriminadores em relação aos negros e mulatos. ${ }^{46}$ No seio da própria elite, se um negro ou mestiço chegasse tão longe - e bem poucos fora das Antilhas francesas chegaram a essas posições elevadas - a discriminação era provavelmente menos pronunciada, uma vez que a classe formava uma barreira muito mais rígida do que a raça. Mas mesmo esse status não garantia igualdade, e os lavradores de cor livres de Saint Domingue (futuro Haiti) enfrentaram uma amarga hostilidade da elite rural branca, o que foi um dos principais fatores que preparam o caminho para a rebelião de escravos de $1791 .^{47}$ Não se tratava de uma elite branca amedrontada a atacar gratuitamente os de cor

${ }^{44}$ Tannebaum, Slave and Citizen.

45 Ver Cope, The Limits of Racial Domination.

46 Susan Socolow: "Acceptable Partners: Marriage Choice in Colonial Argentina, 1778-1810", in Asunción Lavrín (org.), Sexuality and Marriage in Colonial Latin America (Lincoln: University of Nebraska Press, 1989), pp. 209-46.

47 Yvan Debbasch, Couleur et liberte. Le jeu du critère ethnique dans un order juridique esclavagiste, Paris : Dalloz, 1967; e mais recentemente Laurent Dubois, Avengers of the New World: The Story of the Haitian Revolution, Cambridge: Belknap Press of Harvard University, 2004. 
como um elemento perigoso a suas sociedades, como ocorreu no caso da suposta conspiração de La Escalera, em Cuba, no início da década de $1840 .{ }^{48}$ A cor era claramente um indicador de status na sociedade latino-americana, mas a definição de classe, status e de identidade envolvia mais indicadores do que apenas a cor da pele. Isso constituiu um nítido contraste com os Estados Unidos e as colônias inglesas, onde a cor da pele era a única marca usada para discriminar as pessoas, tornando assim mais fácil o funcionamento do preconceito.

E quanto à vida religiosa e social dos escravos e das pessoas livres de cor? Embora os países católicos batizassem os escravos africanos, desde os primeiros dias de sua chegada nas Américas, a Igreja teve um impacto apenas moderado sobre seus cotidianos. Descanso nos feriados religiosos e domingos eram geralmente obrigatórios, e a muitos escravos eram ensinados os princípios básicos do cristianismo. Não houve nenhuma hesitação da Igreja romana na incorporação dos africanos como seus membros, em contraste com as igrejas protestantes que retardaram a aceitação destes por um longo tempo. Todos os escravos recebiam os sacramentos e participavam dos rituais da Igreja, desde que um sacerdote estivesse acessível a eles. Mas havia relativamente poucos padres e em geral a vida do escravo cruzou apenas moderadamente com a eclesiástica, especialmente nas áreas rurais. Mas a Igreja obrigava os feriados e muitos católicos respeitavam esses dias sem trabalho. A Igreja foi também um local de alforrias (na pia batismal) e há muitas evidências do seu apoio aos escravos que eram casados. Todos os escravos tomavam parte nos sacramentos e quase todos usavam os rituais de compadrio para reforçar laços sociais, tanto na comunidade escrava quanto na dos livres e libertos. Finalmente, no Brasil, há provas abundantes, na região Sudeste, de casamentos legais de escravos, juntamente com os esforços sistemáticos da Igreja para garantir que os casais permanecessem juntos, mesmo que filhos adolescentes não fossem sempre protegidos da separação familiar por venda, doação, partilha ou outros métodos. Embora casamentos de escravos pudessem acontecer

${ }^{48}$ Robert L. Paquette, Sugar Is Made with Blood: The Conspiracy of La Escalera and the Conflict between Empires over Slavery in Cuba, Middletown: Wesleyan University Press, 1988. 
no México e em outras sociedades latino-americanas, eles foram relativamente mais importantes no Brasil. ${ }^{49}$

Onde a Igreja teve um impacto maior foi entre as pessoas de cor livres e libertas. Foram estas que organizaram as famosas irmandades religiosas e até conseguiram construir suas próprias igrejas, como pode ser visto em muitas cidades brasileiras. Toda cidade tinha uma irmandade do Rosário - em algumas cidades grandes, como Salvador, cada freguesia tinha uma - e muitas eram inicialmente referenciadas na origem africana específica de seus membros. Estudos recentes têm sugerido que uma minoria significativa dos escravos e negros livres eram membros dessas irmandades. Elas claramente serviram também como eficazes sociedades funerárias, que se encarregavam dos enterros de seus membros. Isso não quer dizer que a atividade religiosa não fosse importante nas sociedades protestantes, mas a autonomia das irmandades foi formalmente reconhecida pelo clero e elas eram uma parte fundamental da sociedade tanto dos brancos quanto dos negros e mestiços livres. Como as milícias, as irmandades religiosas também representaram importantes vias de ascensão e reconhecimento sociais para estes setores livres e libertos, e mesmo escravos. ${ }^{50}$

É evidente que a mais longa história do tráfico da maior região escravista foi um fator fundamental na transmissão e na sobrevivência

49 Sobre casamentos entre escravos rurais na provincial de São Paulo, ver Luna e Klein, Slavery and the Economy of São Paulo, 1750-1850, cap. 6. Para o Rio de Janeiro, ver José Roberto Góes, O cativeiro imperfeito. Um estudo sobre a escravidão no Rio de Janeiro da primeira metade do século XIX, Vitória: Lineart, 1993; e Manolo Florentino e José Roberto Góes, A paz das senzalas. Famílias escravas e tráfico Atlântico, Rio de Janeiro, c.1790 - c.1850, Rio de Janeiro: Civilização Brasileira, 1998. No seu recente estudo sobre casamentos, Slenes mostrou que São Paulo teve taxas mais alta de casamentos de escravos do que a norma, e muito superior ao Rio de Janeiro. Robert W. Slenes, Na senzala, uma flor. Esperanças e recordações na formação da família escrava - Brasil Sudeste, século XIX, Rio de Janeiro: Nova Fronteira, 1999, pp. 82-6.

50 A literatura sobre as confrarias de pessoas de cor é bastante extensa, ver A. J. R. RussellWood, "Black and Mulatto Brotherhoods in Colonial Brazil: A Study in Collective Behavior", The Hispanic American Historical Review, v. 54, n. 4 (1974), pp. 567-602; Roger Bastide, Les religions africaines au Brésil. Contribution à une sociologie des interpénétrations de civilisation, Paris: PUF, 1995; Julita Scarano, Devoção e escravidão: a irmandade de Nossa Senhora do Rosário dos Pretos do Distrito Diamantino do século XVIII, São Paulo: Cia. Editora Nacional, 1976. Sobre relação da devoção do Rosário com a religião banta, ver Juliana Beatriz Almeida de Souza, "Viagens do Rosário entre a Velha Cristandade e o AlémMar", Estudos Afro-Asiáticos, v. 23, n. 2 (2001), pp.1-17. 
das ideias religiosas e dos cultos africanos na América Latina, comparada com as rotas de tráfico menos intensas para a América do Norte. ${ }^{51}$ Mas a sobrevivência das práticas religiosas africanas, tão importantes para as comunidades afro-americanas na América Latina, foi também, em parte, devida à sua capacidade de "sincretizar" com as práticas populares católicas, algo menos viável dentro da religiosidade protestante. ${ }^{52}$

Então, o que podemos dizer, comparativamente, sobre as semelhanças e diferenças entre todas essas sociedades? Parece-me que a maioria das grandes sociedades escravistas continentais, até 1800, movia-se mais ou menos na mesma direção em termos de organização do trabalho, preços de alforria, importância relativa de escravos e senhores e dimensão das escravarias. Cuba e Porto Rico compartilharam a maioria das características desses regimes continentais, e o Caribe inglês e as Antilhas francesas, devido a uma invulgar estrutura demográfica, representaram modelos bastante alternativos. Porém, depois de 1800, os Estados Unidos começaram a se mover em uma direção diferente e, essencialmente, começaram a se opor a tendências correntes de abertura do sistema através do aumento no número de alforrias concedidas e a incorporação dos libertos como membros da sociedade livre.

Como isso aconteceu é fácil de ver, mas responder ao "porquê" é muito mais complicado. Em vez de permitir a evolução econômica e social do regime escravista, como estava ocorrendo em todos os países latino-americanos no século XIX, a elite escravista dos Estados Unidos decidiu que o sistema tinha que ser completamente fechado, negando aos escravos o acesso a alfabetização e liberdade, em uma escala crescente de rigidez. Não é por acaso que os Estados Unidos foram a única sociedade a apresentar uma defesa categórica da escravidão. ${ }^{53}$ Pode ser

${ }^{51}$ Para um exame da relevante literatura sobre esse assunto, ver Herbert S. Klein, The Atlantic Slave Trade, Nova York: Cambridge University Press, 2009.

52 Isso é mais evidente quando comparamos os achados de Bastide com aqueles de Albert J. Raboteau, Slave Religion: The 'Invisible Institution' in the Antebellum South, Nova York: Oxford University Press, 1978; e Mechal Sobel, Trabelin'On: The Slave Journey to an AfroBaptist Faith, Princeton: Princeton University Press, 1988.

53 Ver Barbara Weinstein, "The Destruction of Slavery and the Construction of National Identity: Brazil and the United States South Compared", in Don H. Doyle e Marco Antonio Pamplona (orgs.), Nationalism in the New World (Athens, GA: University of Georgia Press, 2006), pp. 248-71. Para um exame da escola da defesa positiva, ver Drew Gilpin Faust (org.), The Ideology 
que nas sociedades democráticas, elites brancas e trabalhadores livres brancos se sentissem mais assustados com a potencial mobilidade social e econômica das pessoas de cor livres. Esse medo do escravo emancipado provavelmente existiu também na América Latina, mas nunca foi forte o suficiente para criar barreiras rígidas contra o funcionamento econômico normal das economias de mercado. O que é mais estranho nisso é que os norte-americanos estavam lidando com uma população de ascendência africana muito menor, e que de fato teve menos africanos do que era o padrão em outras partes em meados do século XIX. Também não era uma população escrava ameaçada de extinção. Os escravos norte-americanos estavam se reproduzindo em mais de $2 \%$ ao ano - uma taxa, a propósito, igual ao crescimento de negros e mestiços livres no Brasil no século XIX - de modo que nos Estados Unidos a mão de obra escrava poderia ter perdido $1 \%$ desse crescimento com alforrias, e a escravidão e a população escrava ainda poderiam ter sobrevivido.

Também é claro que, quando finalmente emancipado, o negro norte-americano desempenhou um papel muito menos decisivo no mercado do que suas contrapartes na América Latina. ${ }^{54}$ Pequenos agriculto-

of Slavery: Proslavery Thought in the Antebellum South, 1830-1860, Baton Rouge: Louisiana State University Press, 1981. É interessante notar que a primeira defesa positiva da escravidão no Congresso Nacional dos Estados Unidos aconteceu em 1790. Berlin, Slaves without Masters, p. 87.

${ }^{54}$ Sobre a relativa privação das pessoas de cor livres nos Estados Unidos, ver a avaliação geral de Ira Berlin, na obra acima citada. Embora a algumas dessas pessoas fosse permitido ter propriedades, em vários estados a lei foi cruelmente contrária à sua ascensão social. Sobre a exploração econômica de algumas centenas das pessoas mais ricas de cor e livres nos estados escravistas do sul, ver Loren Schweininger, Black Property Owners in the South, 1790-1915, Urbana: University of Illinois Press, 1990; e seu ensaio "Prosperous Blacks in the South, 1790-1880", American Historical Review, v. 95 n. 1 (1990), pp. 31-56. Embora alguns tenham sido bem sucedidos, a norma foi uma grande e ativa discriminação legal e a obstrução da mobilidade social. Em todos os estados do sul lhes era legalmente negado acesso à mobilidade geográfica, foram limitados nas suas ocupações, em seus direitos como pessoas livres, e em muitos estados lhes foi até mesmo negado o direito de casar com brancos. Finalmente, em todos os estados a ascendência negra ou mulata até a terceira geração garantia a classificação como negro. Ver Luther Porter Jackson, Free Negro Labor and Property Holding in Virginia, 1830-1860, Nova York: Atheneum, 1968; John Hope Franklin, The Free Negro in North Carolina, 1790-1860, Nova York: Norton, 1971; James Martin Wright, The Free Negro in Maryland, 1634-1860, Nova York: Columbia University Press, 1921. Tudo isso está em nítido contraste com a relativa prosperidade e mobilidade no Brasil. Sobre a riqueza de pessoas de cor livres no Brasil, ver o artigo de Klein e Paiva citado acima, assim como Herbert S. Klein e Francisco Vidal Luna, "Free Colored in a Slave Society: São Paulo and Minas Gerais in the Early Nineteenth Century", Hispanic American Historical Review, v. 80, n.4 (2000), pp. 913-42. Uma amostra da riqueza entre a primeira geração de ex-escravos foi analisada por Oliveira, $O$ liberto. 
res e artesãos brancos bloquearam a integração dos negros de várias maneiras no sul dos Estados Unidos. Mesmo após a Guerra Civil, tem sido sugerido que o mercado de terras no sul do país permaneceu fechado para a maioria deles. ${ }^{55}$ Se na América Latina um sistema de auxílio mútuo mais estável garantiu a efetiva educação e a capacitação ocupacional aos escravos, há pouca dúvida sobre a capacidade que tiveram ex-escravos de transferir com sucesso suas habilidades profissionais para o mercado de trabalho livre, algo que era muito mais difícil de conseguir nos Estados Unidos, onde uma classe artesã branca se sentia ameaçada pela competição negra. Com a restrição à sua mobilidade física, bem como uma ativa concorrência dos brancos, e provavelmente com treinamento mais rudimentar nas suas tarefas agrícolas, era extremamente difícil para os ex-escravos levar suas habilidades profissionais para além da barreira da liberdade na América do Norte.

Este fechamento de oportunidades para os ex-escravos foi ainda mais evidente quando a emancipação final ocorreu nos Estados Unidos, em 1865. Até 1900, na verdade, bem mais de 90\% dos afro-americanos ainda residiam no sul do país e a discriminação contra eles era onipresente. ${ }^{56}$ Em contraste, no Brasil, por exemplo, poucos ex-escravos podiam ser encontrados no centro das áreas de café e de engenho de açúcar nas planícies do Oeste Paulista após a emancipação, enquanto muitos partiram em busca de terra nas regiões de fronteira ou outras regiões agrícolas decadentes, ou migraram para as cidades em busca de emprego. O trabalho escravo após 1888 foi completamente substituído pelo trabalho do imigrante europeu em todas as regiões cafeeiras. Embora, obviamente, algumas famílias de escravos tivessem permanecido nas áreas de origem, e houvesse distritos no Brasil com índices elevados de moradores negros e pardos, os ex-escravos podiam ser encontrados em todo lugar após a Abolição. De fato, a mobilidade geográfica era a norma em todas as sociedades latino-americanas, tanto antes como após a Abolição. Em contraste, a imobilidade geográfica dos ex-escravos no sul dos EUA durou até o início do século XX.

55 Esse é o argumento sustentado por Roger L. Ransom e Richard Sutch, One Kind of Freedom: The Economic Consequences of Emancipation, Nova York: Cambridge University Press, 2001.

56 Ver Herbert S. Klein, A Population History of the United States, Cambridge: Cambridge University Press, 2004, cap. 4. 
Embora reconhecendo que os libertos, em todos os lugares, eram os mais pobres em todas as sociedades escravistas e ex-escravistas, é, no entanto, evidente que as leis e atitudes que promoveram ou rejeitaram a alforria, e aceitaram ou se opuseram à mobilidade econômica e geográfica dos libertos antes da emancipação foram cruciais em demarcar a condição dessas populações afro-americanas muito depois do fim da escravidão. Se faz sentido este argumento sobre as diferenças fundamentais em relação a variáveis chaves, então é evidente que só podemos explicar as diferenças e seus fatores causais através de trabalho comparativo mais detalhado sobre as atitudes da elite escravista branca em cada sociedade e a natureza dos mercados de trabalho locais. $\mathrm{O}$ porquê de uma classe escravista temer a mudança da condição do escravo e outro grupo aceitar a mudança sem medo de perda de controle pode dever-se a uma série de diferentes fatores políticos e demográficos. Regimes democráticos são mais racistas do que os não-democráti$\cos$ ? As sociedades com menos imigração europeia são mais dispostas a confiar no trabalho qualificado e não qualificado dos afro-americanos do que aquelas que experimentaram a constante imigração de trabalhadores livres brancos? Valores culturais católicos fazem senhores de escravos aceitarem mais a alforria do que a cultura protestante? Como as Antilhas francesas se encaixam nesse esquema?

Claramente, acredito que para responder a essas questões sobre diferenças comparativas entre regimes escravistas há várias áreas que vale a pena investigar em detalhe. Para começar, há o papel econômico dos escravos, o capital humano que eles acumularam sob a escravidão e a disponibilidade de papeis alternativos dentro da escravidão que pudessem permitir o acesso às habilidades, o distanciamento do controle diário do senhor e outras formas de autonomia social e econômica, fossem elas individuais ou coletivas, religiosas ou civis. Ainda a ser considerada é a taxa de crescimento e a importância da alforria e o apoio legal e eficaz que lhe foi dada pela classe senhorial. Finalmente, precisamos considerar o papel das pessoas de cor livre bem antes da emancipação final dos escravos. Como elas surgiram, qual a sua proporção em relação aos brancos e escravos, onde viviam, quais e como eram as suas instituições e comunidades, e quanto de suas habilidades aprendidas sob a escravidão estava disponível para elas como libertas. Qual era a 
natureza do racismo e como funcionou por classe e cor? Tudo isso requer um estudo da natureza da concorrência entre brancos e negros no mercado de trabalho livre, e da atitude da classe trabalhadora branca em relação a seus pares afro-americanos. Também nos obriga a estudar a elite e sua atitude frente à escravidão, os escravos e os negros livres e libertos no seu meio. Como já defendi durante muitos anos, precisamos examinar as pessoas de cor livres no tempo da escravidão para entender completamente os regimes escravistas. Estas são apenas algumas das áreas a explorar, se quisermos explicar as diferenças óbvias que existiram entre as sociedades escravistas nas Américas. Além disso, explicar tanto as características comuns quanto as diferenças nas sociedades escravistas americanas, e a posição dos negros e mestiços livres nestas, já será percorrer um longo caminho para fazer entender os diferentes padrões de integração de todos os afro-americanos no período pós-escravista.

\title{
Texto recebido em 2/3/2011 e aprovado em 24/06/2011
}

\begin{abstract}
Resumo
Este ensaio reconsidera o tema das diferenças comparativas em sistemas escravistas no Novo Mundo. Apesar da rejeição a quaisquer diferenças comparativas de norte-americanos no último quarto de século, pesquisas recentes têm mostrado importantes variações nesses regimes. Essas variações dependem de diferenças entre os mercados de trabalho, nas estruturas demográficas e, sobretudo, nas atitudes face à alforria e à classe de pessoas de cor livres anteriores à emancipação. Apesar de todos os regimes escravistas de plantation terem muito em comum, houve diferenças na participação de escravos e de pessoas de cor livre em ocupações não agrícolas. Isso muitas vezes dependia da disponibilidade de mão-de-obra branca alternativa. Além disso, no século XIX, muitos dos regimes latinoamericanos aumentaram o ritmo das alforria e aprenderam a aceitar os de cor livres como parte fundamental de sua economia, mesmo ao adotar atitudes racistas em relação aos novos libertos. Ao mesmo tempo, os Estados Unidos e alguns dos regimes de plantation do Caribe diminuíram o ritmo de alforria e criaram severas restrições à mobilidade espacial, social, geográfica e econômica a sua pequena classe livre de cor. As causas e consequências dessas diferenças são discutidas neste ensaio.
\end{abstract}

Palavras-chave: afro-americanos - escravidão - agricultura de plantation mobilidade social - mobilidade econômica 


\begin{abstract}
This essay reconsiders the theme of the comparative differences in slave systems in the New World. Despite the rejection, by North American scholars over the past quarter century, of any comparative differences, recent research has shown important variations in the slave regimes. These variations depended on differences in labor markets, in demographic structures and above all in attitudes towards manumission and the class of free colored persons prior to emancipation. Although all slave plantation regimes shared much in common, there were differences in the participation of slaves and free colored in nonagricultural and non-plantation occupations. This often depended on the availability of alternative white labor. Moreover in the 19th century many of the Latin American regimes increased the pace of manumission and learned to accept the free colored as a fundamental part of their free economy even while adopting racist attitudes toward them. At the same time the United States and some of the Caribbean plantation regimes slowed the pace of manumission and created severe restrictions on the social, geographic and economic space and mobility of their small free colored class. The causes and consequences of these differences are discussed in this essay.
\end{abstract}

Keywords: Afro-Americans - slavery-plantation agriculture - social mobility - economic mobility 